\title{
Systolic and diastolic blood pressures as predictors of coronary heart disease mortality in the Whitehall study
}

\author{
M J LICHTENSTEIN, M J SHIPLEY, G ROSE
}

\begin{abstract}
Systolic and diastolic blood pressures were compared as predictors of death due to coronary heart disease using data on the 10 year mortality outcome from the 18403 male civil servants, aged $40-64$, in the Whitehall study. There were 727 deaths due to coronary heart disease. At entry to the study the systolic pressure in these men was significantly higher than the diastolic pressure, and a standardised index of relative risk for death from coronary heart disease was greater for systolic blood pressure. After adjustment for age the top quintile of systolic pressure $(>151 \mathrm{~mm} \mathrm{Hg})$ identified $5 \%$ more men at risk of death from coronary heart disease than for the top diastolic quintile $(>95 \mathrm{~mm} \mathrm{Hg}$ ). The findings suggested that clinicians should pay more attention to systolic levels as a criterion for making diagnostic and therapeutic decisions.
\end{abstract}

\section{Introduction}

The first published trials concerning the treatment of raised blood pressure used the level of diastolic pressure as the main criterion for entry into study. ${ }^{1-3}$ Subsequent trials have used combinations of levels of diastolic and systolic pressure. ${ }^{4-6}$ Textbooks $^{7}$ and committee recommendations ${ }^{8}$ have briefly mentioned the systolic level but focus on the diastolic level as the primary index for making diagnostic and treatment decisions. Is the use of a diastolic end point the best criterion for identifying a level of blood pressure that is clinically important? While diastolic and systolic pressures are both predictive of death from coronary heart disease, longitudinal epidemiological studies have consistently suggested that in men aged over 40 systolic pressure is slightly better. ${ }^{9-13}$ Individually these studies have not been large enough to reduce convincingly the probability that chance caused the observed differences between the two highly correlated variables of diastolic and systolic pressure.

The Whitehall study provides a data base several times larger than any previous investigation of this problem. We examined three issues: $(a)$ the relative rises of systolic and diastolic pressure in subjects dying of coronary heart disease; (b) the relative risk of coronary heart disease associated with comparable rises of either systolic or diastolic pressure; and (c) the use of systolic levels to enhance the clinical identification of persons at risk of dying from coronary heart disease.

\footnotetext{
Medical Research Council Epidemiology Unit, Cardiff CF2 3AS, Wales

M J LICHTENSTEIN, MD, MSC, Milbank Memorial Fund scholar

Department of Epidemiology, London School of Hygiene and Tropical Medicine, London WC1 7HT

M J SHIPLEY, MSC, statistician

G ROSE, DM, FRCP, professor

Correspondence to: Dr M J Lichtenstein.
}

\begin{abstract}
Methods
The Whitehall study is a longitudinal study of 18403 male British civil servants, aged 40-64, who underwent a screening survey for cardiorespiratory disease and its risk factors in 1968-70.14 In the following 10 years 1669 deaths occurred, of which $727(44 \%)$ were coded by the Office of Population Censuses and Surveys as due to coronary heart disease (ICD-8/410-414: acute myocardial infarction, angina pectoris, chronic ischaemic heart disease). The results of the screening survey and the 10 year mortality outcome provide the data base for this analysis. ${ }^{15}$
\end{abstract}

\section{SURVEY PROCEDURES}

Details of the examination procedures have been published. ${ }^{14} \mathrm{~A}$ single blood pressure measurement was taken from the left arm of a seated subject. Systolic blood pressure was recorded at the first appearance of the Korotkoff sounds; diastolic pressure was recorded at both the muffling (phase IV) and disappearance (phase V) of the Korotkoff sounds. The two diastolic variables were highly correlated and only the phase IV level is reported here as both variables gave similar results. The blood pressure cuffs used measured $13.5 \mathrm{~cm} \times$ $22 \mathrm{~cm}$. To reduce bias and variation observers were specially trained ${ }^{16}$ and used the London School of Hygiene sphygmomanometer. ${ }^{17}$

\section{STATISTICAL METHODS}

As systolic and diastolic blood pressures differ in range and variance standard normal deviates adjusted for age were calculated and compared. Firstly, the means (SD) of systolic and diastolic levels within each five year age group were computed. An age specific standard normal deviate for both systolic and diastolic pressures for each subject was then obtained in the following manner: standard normal deviate $=$ (observed blood pressure - mean age specific blood pressure)/age specific standard deviation. The resulting standard normal deviates, when averaged, had a mean of zero and a variance of one.

The standard normal deviate indicates the degree to which a person's pressure (whether systolic or diastolic) deviates from an age specific mean. If the null hypothesis of no difference between the relative rises in systolic and diastolic pressures in subjects dying of coronary heart disease is true the average difference in those subjects would tend to zero. Significance was assessed by a paired $t$ test.

Multiple logistic regression analysis was used to examine the contributions of systolic and diastolic pressures to coronary heart disease mortality outcome, and we allowed for confounding factors. ${ }^{18}$ Systolic pressure, diastolic pressure, age, and body mass index were entered as continuous independent variables. Current cigarette smoking, being an ex-smoker, angina pectoris, and electrocardiographic findings suggestive of ischaemia were entered as dichotomous variables. Standardised regression coefficients were calculated by multiplying the regression coefficient by the standard deviation of the variable, and from these standardised relative risks were computed by exponentiation. The standardised relative risks indicated the relative change in risk associated with a change of one standard deviation in the continuous variable of interest.

\section{Results}

Tables I and II show the effects of age on blood pressure measurements. The expected gradient of increasing levels of systolic pressure with advancing age was seen in each category. A smaller and less consistent rise was also seen in diastolic levels with the mean pressures tending to be lower in the 60-64 year age group. The mean values 
TABLE I-Systolic blood pressure and standard normal deviates by age group and 10 year mortality outcome

\begin{tabular}{|c|c|c|c|c|c|c|}
\hline \multirow[b]{2}{*}{ Age (years) } & \multicolumn{3}{|c|}{ Patients who died of coronary heart disease } & \multicolumn{3}{|c|}{ Patients alive at 10 years } \\
\hline & No of cases & $\begin{array}{l}\text { Mean (SD) systolic blood } \\
\text { pressure }(\mathrm{mm} \mathrm{Hg})\end{array}$ & $\begin{array}{l}\text { Mean (SD) standard } \\
\text { normal deviate }\end{array}$ & No of cases & $\begin{array}{l}\text { Mean (SD) systolic blood } \\
\text { pressure }(\mathrm{mm} \mathrm{Hg})\end{array}$ & $\begin{array}{l}\text { Mean (SD) standard } \\
\text { normal deviate }\end{array}$ \\
\hline $\begin{array}{l}40-44 \\
45-49 \\
50-54 \\
55-59 \\
60-64\end{array}$ & $\begin{array}{r}27 \\
92 \\
165 \\
242 \\
201\end{array}$ & $\begin{array}{l}130.5(18.2) \\
142.2(23.0) \\
142.5(24.4) \\
150 \cdot 1(31 \cdot 1) \\
154.4(28.4)\end{array}$ & $\begin{array}{l}0.01(1.04) \\
0.54(1.25) \\
0.34(1.16) \\
0.47(1.09) \\
0.42(1.13)\end{array}$ & $\begin{array}{l}2699 \\
4744 \\
3937 \\
3439 \\
1909\end{array}$ & $\begin{array}{l}130.4(15.6) \\
131.9(13.8) \\
135.1(18.8) \\
138.5(23.5) \\
143.3(21.8)\end{array}$ & $\begin{array}{r}0.00(1.04) \\
0.01(0.69) \\
-0.02(1.25) \\
-0.05(1.17) \\
-0.06(0.87)\end{array}$ \\
\hline
\end{tabular}

TABLE II-Diastolic blood pressure and standard normal deviates by age group and 10 year mortality outcome

\begin{tabular}{|c|c|c|c|c|}
\hline \multirow[b]{2}{*}{ Age (years) } & \multicolumn{2}{|c|}{ Patients who died of coronary heart disease } & \multicolumn{2}{|c|}{ Patients alive at 10 years } \\
\hline & $\begin{array}{l}\text { Mean (SD) diastolic blood } \\
\text { pressure }(\mathrm{mm} \mathrm{Hg})\end{array}$ & $\begin{array}{l}\text { Mean (SD) standard } \\
\text { normal deviate }\end{array}$ & $\begin{array}{c}\text { Mean (SD) diastolic blood } \\
\text { pressure }(\mathrm{mm} \mathrm{Hg})\end{array}$ & $\begin{array}{l}\text { Mean (SD) standard } \\
\text { normal deviate }\end{array}$ \\
\hline $\begin{array}{l}40-44 \\
45-49 \\
50-54 \\
55-59 \\
60-64\end{array}$ & $\begin{array}{l}84.4(13 \cdot 5) \\
90.3(14 \cdot 4) \\
88 \cdot 5(15 \cdot 4) \\
92 \cdot 1(17 \cdot 1) \\
90 \cdot 3(17 \cdot 0)\end{array}$ & $\begin{array}{l}0.20(1.04) \\
0.50(1.06) \\
0.28(1.16) \\
0.44(1.09) \\
0.25(1.13)\end{array}$ & $\begin{array}{l}81.9(10.4) \\
83.4(13.8) \\
84.4(12.5) \\
85.2(11.7) \\
85.9(13.1)\end{array}$ & $\begin{array}{r}0.00(1.04) \\
-0.02(0.69) \\
-0.02(1.25) \\
-0.04(1.17) \\
-0.05(0.87)\end{array}$ \\
\hline
\end{tabular}

for systolic and diastolic pressure were significantly greater for those dying of coronary heart disease than for those alive after 10 years in all age groups except $40-44$ years. The mean standard normal deviate values were also greater for those dying of cornary heart disease, but they showed no general increase with advancing age. In the group dying of coronary heart disease the standard normal deviate for systolic pressure was slightly but consistently greater than that for diastolic pressure in all but the youngest age group; the difference was significant only in the 60-64 year age group. Table III shows that the mean standard normal deviates for systolic and diastolic pressure were all significantly greater for those subjects dying of coronary heart disease than for those still living after 10 years of follow up. For men dying of coronary heart disease the mean difference between the standard normal deviates for systolic and diastolic pressure was 0.07 and significant $(p<0.05)$ with or without logarithmic transformation. Men dying of coronary heart disease therefore have a systolic pressure that deviates from the mean for their age specific group to a small but significantly greater extent than does their diastolic pressure.

Age, body mass index, cigarette smoking, angina pectoris, and ischaemic electrocardiographic findings may all have been associated with the level of blood pressure at the time of screening in those subjects who eventually died of coronary heart disease. Multiple logistic regression analysis was performed to adjust for these variables and explore the relative strengths of systolic and diastolic pressures in predicting death from coronary heart disease. Table IV contains standardised relative risks for systolic and diastolic pressures with their $95 \%$ confidence intervals. The results show the greater reduction in relative risk associated with diastolic pressure after adjustment for

TABLE III-Mean (SD) standard normal deviates adjusted for age for systolic and diastolic pressures and their difference by 10 year mortality outcome

\begin{tabular}{lcc}
\hline & $\begin{array}{c}\text { Patients who died of } \\
\text { coronary heart disease } \\
(\mathrm{n}=727)\end{array}$ & $\begin{array}{c}\text { Patients alive at } \\
10 \text { years } \\
(\mathrm{n}=16728)\end{array}$ \\
\hline Systolic & $0.42(1.08)^{* * * *}$ & $-0.03(1.29)^{* * *}$ \\
Diastolic & $0.35(1.08)^{* * * *}$ & $-0.02(1.29)^{* *}$ \\
Systolic - diastolic & $0.07(0.81)^{* *}$ & $0.00(1.29)$ \\
\hline
\end{tabular}

${ }^{*} \mathrm{p}<0.05 ;{ }^{* *} \mathrm{p}<0.01 ;{ }^{* * *} \mathrm{p}<0.001$

TABLE IV-Standardised relative risks of systolic and diastolic blood pressures for death from coronary heart disease from multiple logistic regression analysis*

\begin{tabular}{lcc}
\hline \multicolumn{1}{c}{$\begin{array}{c}\text { Blood pressure } \\
\text { variable in model }\end{array}$} & $\begin{array}{c}\text { Standardised } \\
\text { relative risk }\end{array}$ & $\begin{array}{c}9{ }^{\prime} \text { "confidence } \\
\text { interval }\end{array}$ \\
\hline Systolic alone & 1.37 & $1 \cdot 28-1 \cdot 47$ \\
Diastolic alone & 1.31 & $1.22-1 \cdot 44$ \\
Systolic adjusted for diastolic & 1.29 & $1.17-1.43$ \\
Diastolic adjusted for systolic & 1.09 & $0.99-1 \cdot 20$ \\
\hline
\end{tabular}

-Relative risks adjusted for age, body mass index, smoking, angina pectoris, and isc haemic electrocardiographic findings. systolic levels. The adjusted relative risk for systolic pressure was significantly greater than that for diastolic pressure. The standardised $\Theta$ relative risk for systolic pressure remains significant after adjustment 0 for diastolic levels, whereas the $95 \%$ confidence interval for the $\vec{\omega}$ diastolic standardised relative risk just includes 1.0. The addition of 0 systolic pressure after diastolic pressure significantly improves the regression estimates of risk of coronary heart disease, but the addition of diastolic pressure after systolic pressure does not.

How much does this difference in standard normal deviates and relative risks influence the clinical identification of subjects at $\vec{\theta}$ increased risk of fatal coronary heart disease? The mortalities from $\mathscr{C}_{\infty}$ coronary heart disease in the upper quintiles of systolic $(>151 \mathrm{~mm}$. $\mathrm{Hg}$ ) and diastolic $(>95 \mathrm{~mm} \mathrm{Hg})$ pressures were 7.79 and $6.79 \mathrm{O}$ deaths $/ 100 \mathrm{men} / 10$ years, respectively. The rate ratio of 1.15 suggests that $15 \%$ more men could have been identified as being at higher risk of dying from coronary heart disease if the systolic pressure rather than the diastolic pressure had been measured. After adjustment $\frac{\mathrm{Q}}{\varnothing}$ for age, however, the rate ratio was $1 \cdot 05$.

\section{Discussion}

The standard normal deviates in this study were calculated for each subject within five year age groups and then averaged for each cause of death. In contrast the Framingham study compared levels of age specific mean blood pressure between $\frac{0}{3}$ groups dying of heart disease and those still living. ${ }^{10}$ The findings of the Framingham study are nevertheless similar-o the standardised mean differences for death due to coronary heart disease were 0.41 for systolic pressure and 0.28 for diastolic 은 pressure, while in this study they were 0.42 and 0.35 , respec- N tively; the difference between the figures from the Whitehall $\rightarrow$ study was small but significant.

After adjustment for age, body mass index, angina pectoris, smoking, and electrocardiographic abnormalities the standardised $\mathrm{N}$ relative risk of death from coronary heart disease was 1.37 for $\omega$ systolic pressure and 1.31 for diastolic pressure. When either systolic or diastolic pressure is adjusted for the other the standardised relative risk becomes 1.27 for systolic and 1.09 for $\mathbb{Q}$ diastolic. These findings are similar to those of the Western? Collaborative Group study. ${ }^{11}$ An index of both measurements 0 (mean arterial pressure - diastolic pressure $+1 / 3$ (systolic- $-\frac{P}{D}$ diastolic pressure)) provides an estimate of risk equal to but $\frac{\mathcal{O}}{\mathbb{D}}$ not greater than that associated with systolic pressure alone. $\varrho$ Systolic pressure, as a measurement of blood pressure, is a? slightly better indicator of risk than diastolic pressure when 0 each is considered alone. When adjusted for each other the risk을 associated with systolic pressure is significantly greater $\operatorname{than}_{\underline{\hat{0}}}$ that associated with diastolic pressure.

Fifteen per cent more subjects who would subsequently die of coronary heart disease were identified when the systolic level 
was used as a diagnostic criterion, but this proportion was reduced to $5 \%$ after adjusting for age.

Three factors may contribute to the observation that systolic pressure is slightly superior to diastolic pressure as a predictor of death from coronary heart disease. Firstly, the larger range between subjects for systolic pressure may more readily identify those at risk for coronary heart disease; secondly, as systolic levels depend partly on arterial compliance ${ }^{19}$ they may provide a better reflection of the degree of underlying arterial disease; and, thirdly, arterial injury may be related more to peak than to mean pressures.

As systolic levels are easier to measure than diastolic levels how would they compare as a guide to the control of high blood pressure? Some information on this might be provided if the data of the completed blood pressure intervention trials were reanalysed so as to relate outcome to systolic and diastolic pressure control considered separately. Meanwhile, future trials of hypertension might do well to use systolic levels alone, or combined with a diastolic index, as their entry criterion. Clinicians tend to concentrate exclusively on the diastolic level when making a diagnosis of hypertension and in instituting and regulating drug treatment; they should be encouraged to pay more attention to systolic pressure.

\section{References}

1 Veterans Administration cooperative study group on antihypertensive agents. A double blind
2 Hypertension detection and follow-up program cooperative group. The hypertension detection and follow-up program. Prev Med 1976;5:207-15.

Multiple risk factor intervention trial research group. Multiple risk factor intervention trial: risk factor changes and mortality results. $\mathcal{f} A M A 1982$;
248:1465-77.

4 Medical Research Council Working Party on mild to moderate hypertension. Randomised controlled trial of treatment for mild hypertension: design and pilot trial. Br Med F 1977; : 1437-40.

5 Report of the Management Committee. The Australian therapeutic trial in mild hypertension. Lancet $1980 ; \mathrm{i}: 1201-7$

Helgeland A. Treatment of mild hypertension: a five year controlled trial. The Oslo study. Am 7 Med 1980;69:725-32.

Isselbacher, KJ, Adams RS, Braunwald E, Petersdorf RG, Wilson JD, eds Harrison's principles of

8 Report of the Joint National Committee on detection, evaluation and treatment of high blood pressure. Arch Intern Med 1980;140:1280-5.

9 Keys A, Taylor HL, Blackburn H, Brozek J, Anderson J T, Simonson E. Mortality and coronary heart disease among men studied for 23 years. Arch Intern Med 1971;128:201-14

10 Kannel WB, Gordon T, Schwarz MJ. Systolic versus diastolic blood pressure and risk of coronary heart disease. Am $\mathcal{F}$ Cardiol $1971 ; 27: 335-45$.

11 Rosenman RH, Sholtz RI, Brand RJ. A Study of comparative blood pressure measures in predicting risk of coronary heart disease. Circulation 1976;54

12 Rabkin SW, Mathewson AL, Tate RB. Predicting risk of ischaemic heart disease and cerebrovascular disease from systolic and diastolic blood pressures.

13 Miall WE. Systolic or diastolic hypertension-Which matters most ? Clin Exp

Hypertens $[A] 1982 ; 4: 1121-31$.
14 Reid DD, Hamilton PJS, Keen Hett GZ, Jarrett RJ, Rose GA. Cardiorespiratory disease and diabetes among middle aged male civil servants: study of screening and intervention. Lancet $1974 ; \mathrm{i}: 469-73$.

15 Reid DD, Hamilton PJS, McCartney P, Rose GA, Jarrett RJ, Keen H. Smoking and other risk factors for coronary heart disease in British civil servants. Lancet 1976;ii:979-84.

16 Rose GA. Standardization of observers in blood pressure measurement. Lancer 1965 ; $: 673-4$.

17 Rose GA, Holland WW, Crowley EA. A sphygmomanometer for epidemiologists. Lancet $1964 ; \mathrm{i}: 296-300$

18 Breslow NE, Day NE. Statistical methods in cancer research. Vol 1. The analysis of case-control studies. Lyons: International Agency for Research on Cancer, Randall OS. Effect of arterial compliance on systolic blood pressure and cardiac
function. Clin Exp Hypertens $[A] 1982 ; 4: 1045-57$.

\title{
Importance of hypovolaemic shock and endoscopic signs in predicting recurrent haemorrhage from peptic ulceration: a prospective evaluation
}

\author{
P C BORNMAN, N A THEODOROU, R D SHUTTLEWORTH, H P ESSEL, I N MARKS
}

\begin{abstract}
The incidence of rebleeding was studied prospectively in 177 patients with acute gastrointestinal haemorrhage from peptic ulceration with reference to the degree of haemodynamic insult on admission and the presence of endoscopic signs of recent haemorrhage on initial endoscopy.

Rebleeding occurred in two $(2 \%)$ of 114 patients without shock, in seven (18\%) of 38 with tachycardia (pulse rate $>100$ beats $/ \mathrm{min}$, systolic blood pressure $>100 \mathrm{~mm} \mathrm{Hg}$ ), and in $12(48 \%)$ of 25 with shock (systolic blood pressure $<100 \mathrm{~mm}$ Hg). A similar gradient was noted with the presence of endoscopic signs alone. Rebleeding occurred in four (5\%) of 79 patients with no endoscopic signs, in
\end{abstract}

Surgical Gastroenterology Unit, Gastrointestinal Clinic, and Departments of Surgery and Medicine, University of Cape Town, Groote Schuur Hospital, Cape Town, South Africa

P C BORNMAN, MMED(SURG), FRCSED, senior surgeon and senior lecturer in surgery

N A THEODOROU, FRCSED, FRCS, travelling fellow

R D SHUTTLEWORTH, FCSSA, FRCSED, consultant surgeon

H P ESSEL, research assistant

I N MARKS, MSC, FRCPED, head of gastrointestinal clinic

Correspondence to: Dr P C Bornman, gastrointestinal clinic. none of 40 with black spot only, in $11(23 \%)$ of 48 with a clot, and in five $(50 \%)$ of 10 with a visible vessel on endoscopy. When the incidence of rebleeding was assessed in shocked patients, however, it was significantly higher in those with important signs (clot or visible vessel), in $11(79 \%)$ out of 14 patients, than in those with no signs, in one $(9 \%)$ out of $11(p<0.001)$.

These data suggest that the association of shock with important endoscopic signs is a stronger predictor of rebleeding than either shock or important signs alone. More aggressive treatment may be warranted in this small group of patients.

\section{Introduction}

The overall mortality from a single episode of bleeding from peptic ulceration is low. A subsequent haemorrhage, however, during the same admission increases mortality appreciably, particularly in elderly patients. ${ }^{1-5}$ The accurate identification of the few patients likely to rebleed is therefore important.

Recently, endoscopic signs of recent haemorrhage (presence of an old or fresh clot or a visible vessel) within the crater of the ulcer have received attention as useful predictors of further haemorrhage. The incidence of emergency operations for rebleeding in patients with peptic ulceration and any sign of recent haemorrhage has been variably reported between 27 and $53 \%{ }^{6-8}$ 